\title{
Evaluation of the Periodontal Status of Rural Populations in the Ferlo (Senegal)
}

\author{
Diouf Massamba ${ }^{1,}$,, Boetsch Gilles ${ }^{1}$, Cissé Daouda ${ }^{2}$, Tal-Dia Anta ${ }^{3}$, Barro Ibrahima ${ }^{1}$, \\ Bonfil Jean Jacques ${ }^{4}$
}

${ }^{1}$ CNRS - UMI"Environment, Health, Society", Faculty of Medicine, Pharmacy and Dentistry, Dakar, Fann, Senegal

${ }^{2}$ Public Health Office, Department of Dentistry, Cheikh Anta Diop University, Dakar, Senegal

${ }^{3}$ Preventive Medicine and Public Health, Cheikh Anta Diop University, Dakar, Senegal

${ }^{4}$ Faculty of Odontology, bd Jean Moulin Marseille, Cedex

Email address:

dioufmass78@yahoo.fr (D. Massamba),mass78@voila.fr (D. Massamba)

\section{To cite this article:}

Diouf Massamba, Boetsch Gilles, Cissé Daouda, Tal-Dia Anta, Barro Ibrahima, Bonfil Jean Jacques. Evaluation of the Periodontal Status of Rural Populations in the Ferlo (Senegal). Science Journal of Public Health. Vol. 3, No. 5, 2015, pp. 770-774. doi: 10.11648/j.sjph.20150305.35

\begin{abstract}
Introduction: Rural populations in the Ferlo, Senegal, are frequently studied, due to the environmental project, the "Great Green Wall," that covers this area. Epidemiological studies on lifestyle suggested the risk of periodontal disease. The objective of this study was to evaluate the periodontal status of the Widou populations in the Ferlo. Methods: This is descriptive cross-sectional study examined 300 men and women over 10 years of age living in the locality of Widou in the Ferlo. They were selected by simple random sampling. Data on demographic characteristics and periodontal status were collected using a modified WHO questionnaire about assessment of periodontal health. Univariate and bivariate analyses based on sextants and individuals as units of analysis, were used to describe and compare variables. The results were considered statistically significant when a p-value was $\leq 5 \%$. Results: The low and average plaque levels involved 58-99\% of the sample. Between $50 \%$ and $75 \%$ of those examined showed average and moderate gingival inflammation. More than half of the sample needed curettage, especially in the posterior sextants. The average values of loss of attachment and pocket depth respectively ranged from $1.03( \pm 1.72) \mathrm{mm}$ to $2.36( \pm 2.45) \mathrm{mm}$ and $3.59( \pm 0.80) \mathrm{mm}$ to $4.3( \pm 1.02)$ mm. Severe periodontitis was significantly associated with sex, age group, marital status and occupation. Conclusion: These results suggest the need to set up functional dental health care structures near the populations and to provide a community-level integrated prevention program.
\end{abstract}

Keywords: Periodontal Status, Ferlo’S Population, Senegal

\section{Introduction}

In recent years, the Ferlo region has been the subject of many publications in the international literature ${ }^{12}$. In 2005, this area of eastern central of Senegal, populated mainly by the Fulani people, hosted the project of the "Grande Muraile Verte" ("Great Green Wall"). This international project, to limit desertification, frequently receives research teams, health and environmental professionals who come from the North or the South and establishment of mechanisms for monitoring human activities in this area have been established. Epidemiological studies by Diouf et al. on lifestyle and oral health of these populations have found food, smoking and oral hygiene behaviours to be unfavourable habits for oral health which increase the risk of periodontal disease ${ }^{11}$. Other studies about the Ferlo reported the use of traditional therapy for the treatment of oral problems ${ }^{10}$. These populations are also attached to beliefs, traditions and magic-religious practices which may be obstacles or hindrances to good oral health ${ }^{10}$. The objective of this study was to evaluate the periodontal status of Widou populations in the Ferlo.

\section{Methodology}

\subsection{Type and Area of Study}

The study was descriptive and cross-sectional and included people living in the centre of Ferlo. The survey took place in Widou-Thiengoli village, at the Middle East Centre of Senegal. The choice of this area was guided by its geographical position in the "Grande Muraille Verte", its polarised population, the existence of functional health 
centre and the vital role it plays in the economy of the Ferlo.

\subsection{Study Population}

The survey covered all persons aged 10 years or more living in the rural community of Widou and surroundings. These people came to be examined during a civic holiday organised by the Rector of the University Cheikh Anta Diop of Dakar.

\subsection{Selection Criteria}

To be included in the study, individuals should have been born in the area or have lived there for at least ten years, presumed to be sufficient time for negative behaviours and attitudes to have an effect on the health of teeth and periodontium, should have adequate general health to allow oral clinical examination and be available and willing to participate in the study.

\subsection{Sample Size and Sampling}

The required sample size was based on a calculation according to the Schwartz formula ${ }^{3}: \mathrm{n}=\left(\varepsilon_{\alpha}\right)^{2} \mathrm{pq} / \mathrm{i}^{2}$ that can be used in cross-sectional studies where $\varepsilon=1.96=$ standardised normal deviate; $\alpha=$ level of significance $=$ $0.05 ; \mathrm{p}=$ prevalence of the health feature (dental caries) found from a pilot survey in $2012=0.89 ; \mathrm{q}=1-\mathrm{p}=0.11 ; \mathrm{i}=$ $5 \%=$ accuracy. These data suggested a sample size of 150 persons. Given that the power of the study increases with the size of the study, this number was multiplied by 2 , giving a size of 300 persons. Participant recruitment was by simple random sampling. After establishing lists of potential participants, 300 people were drawn from the list by chance. When an individual did not meet the selection criteria, he or she was not considered for the investigation and the next person on the list was selected.

\subsection{Data Collection and Study Variables}

The chosen data collection period was a 20 days civic holiday in which teams of doctors, pharmacists and dentists were deployed in the area to provide care, medication and counselling to people. Before administering the questionnaire, the objectives and importance of the survey were explained to the people, for their informed consent. The questionnaire had been pre-tested on 20 people living in a remote village (Tessekere) more than 20 kilometres distant. Data were collected using the WHO modified questionnaire about periodontal status ${ }^{17}$. Four final year dental students, who had been previously calibrated and standardised in using the measurement technique acted as investigators. This was done to limit information bias. Data collection took place every day (from August 20 to 30, 2013) and concerned all persons living in the community and who met the selection criteria. The information to be collected included: the socio-demographic characteristics (sex, age, education, marital status, occupation) and periodontal status assessed by the plaque index (PLI) of Silness and Lö ${ }^{4}$, the papillary bleeding index (PBI) of Saxer and Muhlemann ${ }^{15}$, periodontal treatment needs 1,9 , clinical attachment loss (CAP) and pocket depth (PD) ${ }^{5,6}$.

\subsection{Ethical Considerations}

Before examination, each individual, provided free and informed consent. After performing the clinical examination, each person enjoyed a motivational and oral hygiene instruction session and received a pack containing a toothbrush and toothpaste. The information from each individual was treated confidentially.

\subsection{Data Analysis}

Epi Info 3.4.5 software was used to capture and process data in univariate and bivariate analyses. The values of certain variables were grouped for statistical treatment for epidemiological interest; this included "age" ( $\leq 35$ and $>35$ years) and "occupation" (farmer/other). Severe periodontitis with (PAC $\geq 5 \mathrm{~mm}$ ) was determined from measures adapted from the Armitage classification ${ }^{4}$. The results of the univariate analysis were expressed as numbers, proportions and averages with standard deviations. The bivariate comparison of proportions was made by $\mathrm{Chi}^{2}$ test and its variants and means by Student's $t$-test. The analyses focused on individuals and sextants. The results were statistically significant when the p-value was less than $5 \%$.

\section{Results}

Table I. Proportion of people per sextant according to the plaque index and papillary bleeding index.

\begin{tabular}{|c|c|c|c|c|c|c|}
\hline Index & Sextants & & & & & \\
\hline Plaque & $26 / 27(\%)$ & $11 / 21(\%)$ & $16 / 17(\%)$ & $36 / 37(\%)$ & $31 / 41(\%)$ & $46 / 47(\%)$ \\
\hline Excellent control & 0.4 & 6.0 & 0.7 & 26.1 & 1.1 & 2.0 \\
\hline Average control & 30.6 & 65.6 & 34.4 & 46.1 & 36.1 & 52.2 \\
\hline Low control & 69.0 & 27.7 & 64.9 & 12.2 & 61.4 & 45.8 \\
\hline Bleeding & $26 / 27(\%)$ & $11 / 21(\%)$ & $16 / 17(\%)$ & $36 / 37(\%)$ & $31 / 41(\%)$ & $46 / 47(\%)$ \\
\hline Moderate inflammation & 20.7 & 18.8 & 19.1 & 20.8 & 18.9 & 20.6 \\
\hline Average inflammation & 55.0 & 33.0 & 53.5 & 51.8 & 52.9 & 51.2 \\
\hline Severe inflammation & 2.2 & 1.1 & 1.1 & 1.2 & 2.5 & 0.4 \\
\hline
\end{tabular}


The "average" plaque control was dominant in the sextants $11 / 21,46 / 47$ and 36/37. "Low" control was high in $26 / 27$ sextants, $16 / 17$ and $31 / 41$. These low and average plaque controls concerned $58 \%(36 / 37)$ to $99 \%$ (26/27) of the sample.

Except for the sextant 11/21, more than half of the sample had an average inflammation in other sextants. More than fifty-one per cent $(51.8 \%)$ in sextant $(11 / 21)$ and $75.7 \%$ in sextant (26/27) of those examined showed "moderate" and "average" gingival inflammation. "Severe" inflammation was observed in a small proportion of the sample (less than $3 \%$ ) for all sextants.

Table II. Proportion of people per sextant according to the Community Periodontal Index of Treatment Needs (CPITN).

\begin{tabular}{|c|c|c|c|c|c|c|}
\hline \multirow{2}{*}{ CPITN } & \multicolumn{6}{|l|}{ Sextants } \\
\hline & $26 / 27(\%)$ & $11 / 21(\%)$ & $16 / 17(\%)$ & $36 / 37(\%)$ & $31 / 41(\%)$ & $46 / 47(\%)$ \\
\hline MT & 12.6 & 31.3 & 14.9 & 21.5 & 21.5 & 19.8 \\
\hline MTS & 20.8 & 10.3 & 19.9 & 20.3 & 28.3 & 12.5 \\
\hline MTSC & 55.8 & 33.5 & 50.9 & 48.0 & 38.0 & 54.8 \\
\hline MTSCX & 7.8 & 1.5 & 6.0 & 2.4 & 5.0 & 2.8 \\
\hline
\end{tabular}

$\mathrm{MT}=$ Motivation + Oral Hygiene Instruction $(\mathrm{OHI})$

MTS $=$ Motivation $+\mathrm{OHI}+$ Scaling

$\mathrm{MTSC}=$ Motivation $+\mathrm{OHI}+$ Scaling + Curettage

MTSCX $=$ Motivation + OHI + Scaling + Curettage + Complex Treatment

More than half of the sample needed «Motivation + OHI + Scaling + Curettage» at all sextants except 11/21, 31/41 and $36 / 37$ for which $48 \%$ of the sample had such needs.

Table III. Mean values of periodontal indices by sextant.

\begin{tabular}{llllll}
\hline $\begin{array}{l}\text { Index (standard } \\
\text { deviation) }\end{array}$ & Sextants & & & \\
\cline { 2 - 6 } & $\mathbf{2 6 / 2 7}$ & $\mathbf{1 1 / 2 1}$ & $\mathbf{1 6} / \mathbf{1 7}$ & $\mathbf{4 6 / 4 7}$ & $\mathbf{3 1 / 4 1}$ \\
\hline Attachment loss in mm & $2.21(2.52)$ & $1.03(1.72)$ & $2.03(2.23)$ & $1.68(1.81)$ & $2.36(2.45)$ \\
Pocket depth in mm & $4.3(1.02)$ & $3.59(0.80)$ & $4.15(0.95)$ & $4.07(0.86)$ & $3.83(1.02)$ \\
\hline
\end{tabular}

Index values were generally higher in the posterior sextants. However, at the sextant (31/41), they were still relatively high.

Table IV. Chi ${ }^{2}$ between severe periodontitis and socio-demographic variables.

\begin{tabular}{|c|c|c|c|c|c|}
\hline \multicolumn{2}{|c|}{ Socio-demographic variables and modalities } & \multicolumn{2}{|c|}{ Severe periodontitis (\%) } & \multirow[t]{2}{*}{$\mathrm{Chi}^{2} \chi^{2}$} & \multirow[t]{2}{*}{ p-value } \\
\hline & & Yes & No & & \\
\hline \multirow{2}{*}{ Sex } & Male & 60 & 40 & \multirow{2}{*}{4.4} & \multirow{2}{*}{0.03} \\
\hline & Female & 71.9 & 28.1 & & \\
\hline \multirow{2}{*}{ Age group (years) } & Young & 17.5 & 82.5 & \multirow{2}{*}{24.9} & \multirow{2}{*}{$<0.001$} \\
\hline & Adult & 44.5 & 55.5 & & \\
\hline \multirow{2}{*}{ Education or literacy } & Yes & 29.0 & 71 & \multirow{2}{*}{0.16} & \multirow{2}{*}{0.68} \\
\hline & No & 32.6 & 67.4 & & \\
\hline \multirow{4}{*}{ Marital status } & Married & 32.4 & 67.6 & \multirow{4}{*}{9.25} & \multirow{4}{*}{0.02} \\
\hline & Single & 7.1 & 92.9 & & \\
\hline & Divorced & 50.0 & 50.0 & & \\
\hline & Widower & 71.4 & 28.6 & & \\
\hline \multirow{2}{*}{ Occupation } & Yes (rancher or farmer) & 39.8 & 60.2 & \multirow{2}{*}{9.61} & \multirow{2}{*}{0.001} \\
\hline & No (housewife ...) & 23.0 & 77.0 & & \\
\hline
\end{tabular}

The occurrence of severe periodontitis was significantly associated with sex, age group, marital status and occupation.

\section{Discussion}

This descriptive and cross-sectional study evaluated the periodontal status of Widou populations in the Ferlo (Senegal) found that low and average plaque scores involved 58-99\% of the sample at different sextants. Similarly, average and moderate inflammation covered between $50 \%$ and $75 \%$ of the sample (Table I). More than half of the sample needed curettage preceded by motivation, oral hygiene instruction and scaling in the posterior sextants except for the sextant $(36 / 37)$ in which $48 \%$ of the sample had the same needs
(Table II). The average values of attachment loss and pocket depth varied respectively from $1.03( \pm 1.72) \mathrm{mm}$ to 2.36 ( \pm $2.45) \mathrm{mm}$ and from $3.59( \pm 0.80) \mathrm{mm}$ to $4.3( \pm 1.02) \mathrm{mm}$ (Table III). Severe periodontitis was significantly associated with sex, age group, marital status and occupation (Table IV). These results show that the periodontal status of these populations is poor. However, these results may display some distortions due to potential bias.

\subsection{Potential Bias}

Although the sampling was random, it was based on individuals seeking health care from staff and students during the civic holiday. It is possible that persons who did not feel the need for care did not participate. Hence, there was a 
possibility of selection bias that would tend to lower the results. Measurement bias due to different interpretations of the periodontal indices should have been minimised, because the four dental students who collected the data had received training and calibration and were already accustomed to such measures.

\subsection{Plaque, Bleeding and Community Treatment Needs Indices}

The plaque and bleeding indices were generally high in the sample (Table I). The qualitative interpretation of these indices, based on sextants, allowed the conclusion that the proportion of individuals with low plaque level was greater in more posterior sextants (Table I). This also occurred for average inflammation score (Table I). A study in Thailand that included several periodontal characteristics showed that oral hygiene was poor with a lot of plaque and calculus; gingival bleeding was ubiquitous, recorded at all sites ${ }^{7}$. The need for periodontal treatment (motivation, oral hygiene instruction, scaling followed by curettage) seems to be more important in the posterior sextants (Table II). The use of the Community Periodontal Index of Treatment Needs (CPITN), a composite index that assesses the periodontal status and the level of periodontal care required, is hotly debated, and is even seen as inappropriate by some authors ${ }^{6,15}$ who qualify it as partial. Indeed, studies using partial recording index underestimate the prevalence and severity of the disease ${ }^{14}$. However, the CPITN remains the benchmark for the $\mathrm{WHO}^{5}$, because it has a standardised international database since 1982 with more than 1000 references ${ }^{9}$. Varenne ${ }^{16}$ in Burkina Faso showed that in general, the periodontal condition is characterised by high levels of gingival bleeding and presence of calculus at young age, especially among people living in rural areas. These facts reflect deficient individual oral hygiene practices associated with adverse eating habits. These rural Ferlo populations are characterised by their links with livestock, which promotes and encourages the consumption of milk. This diet may facilitate the accumulation of plaque on dental surfaces and without rigorous hygiene, this plaque can induce gingival inflammation. Moreover, Diouf et al. in $2012^{11}$ had found that $20 \%$ of periodontal treatment needs in Ferlo were explained by the consumption of milk.

\subsection{Indices of Attachment Loss, Pocket Depth and Periodontitis}

The shallowest pockets $(3.59( \pm 0.80) \mathrm{mm})$ were found in anterior sextants while attachment loss could reach $2.36( \pm$ $2.45) \mathrm{mm}$. In a study conducted in rural areas in the United States in older populations, attachment loss was on average $2.1 \mathrm{~mm}^{12}$. In another study comparing the periodontal status of blacks and whites in the United States, on average $78 \%$ of sites had $4 \mathrm{~mm}$ attachment loss in blacks, versus $65 \%$ of sites in whites with attachment loss of $3.1 \mathrm{~mm}^{8}$. These results suggest that, as the Ferlo population ages, we could end up with more severe attachment loss. In a cross-sectional study of 812 people aged 35 to 74 years in Cambodia to identify factors associated with severe periodontitis, only $12.3 \%$ had sextants with pockets $\geq 4 \mathrm{~mm}^{2}$. The results of our study show a significant proportion of individuals whose periodontal pockets measure more than $4 \mathrm{~mm}$, especially in the posterior sites. Gingival inflammation without treatment and in the presence of poor hygiene may well evolve into incipient periodontitis and severe periodontitis. It appeared that the variables sex, age group, marital status and occupation were significantly associated with severe periodontitis (Table IV). These results are similar to those of most the studies found in the literature ${ }^{2,13}$. Macedo et al. ${ }^{13}$ in Brazil have concluded that the socio-economic and biological factors, including poor oral hygiene and age, were associated with periodontitis in rural communities near the city of Feira de Santana, Brazil.

\section{Conclusion}

The results of the present study show the need to create dental health structures close to populations in integrated community prevention programs, based on education for oral health and oral health care, such as motivation, teaching hygiene, and offering scaling and curettage.

\section{References}

[1] Ainamo J, Barmes D, Beagrie G, Cutress T, Martin J, Sardo Infirri J (1982). Development of the World Health Organization (WHO) community periodontal index of treatment needs (CPITN). Int Dent J.; 32: 281-291

[2] Amarasena N, Ikeda N, Win KK, Yamaguchi Y, Takehara T, Miyazaki H (2004). Factors associated with severe periodontitis in rural Cambodia. Asia Pac J Public Health.16:50-53

[3] Ancelle T (2003). Statistique Épidémiologie. Paris: Éditions Maloine, 300p.

[4] Armitage GC (1999). Development of a classification for periodontal diseases and conditions. Ann. Periodontol. 4: 1-6

[5] Baehni PC, Bourgeois D (1998). Epidemiology of periodontal health and disease. Berlin: Quintessence Publishing. 5: 19-34

[6] Baelum V, Papanou PN (1996). CPITN and the epidemiology of periodontal disease. Community Dent Oral Epidemiol. 24: 367-36

[7] Baelum V, Pisuithanakan S, Teanpaisan R, Pithpornchaiyakul W, Pongpaisal S, Papapanou PN, Dahlén G, Fejerskov O (2003). Periodontal conditions among adults in Southern Thailand. J Periodontal Res.38:156-163

[8] Beck JD, Koch GG, Rozier RG, Tudor GE (1990). Prevalence and risk indicators for periodontal attachment loss in a population of older community-dwelling blacks and whites. J Periodontol.61:521-528

[9] Bourgeois D, Baehni P (2002). Surveillance, épidémiologie et maladies parodontales. Encycl Méd Chir. Paris: Editions Scientifiques et Médicales Elsevier, Odontologie, 23-444-A-10, $6 \mathrm{p}$. 
[10] Diouf M, Boetsch G, Ka K,Tal-Dia A, Bontil JJ (2013). Sociocultural aspects of oral health aùong the Fulani in Ferlo (Senegal): a qualitative study 36:43-48

[11] Diouf M, Boetsch G, Cisse D, Tal-Dia A, Bontil JJ (2012). Lifestyles and oral health in Fulani populations of Ferlo in Senegal. Med Santé Trop. 22:187-192

[12] Diouf M, Boetsch G, Tal-Dia A, Tavitian P, Bontil JJ (2013). Digestive pathology and oral condition in the rural populations of the Ferlo in Senegal. Tropical Dental Journal.141: 1-6

[13] Hunt RJ, Levy SM, Beck JD (1990) The prevalence of periodontal attachment loss in an Iowa population aged 70 and older. J Public Health Dent. 50:251-256

[14] Macedo TC, Costa MDA C, Gomes-Filho IS, Vianna MI (2006). Factors related to periodontal disease in a rural population. Brazilian oral research; 20:257-262.
[15] Papanou PN (1996). Periodontal diseases: epidemiology. Ann Periodontol; 1: 1-36

[16] Saxer U P, Mulhemann H R (1975). Motivaton und Aufklärung. Schweiz. Mschr. Zanhnheilk. 85: 905p

[17] Varenne B (2007). Transition épidémiologique et santé orale au Burkina Faso: Disparités d'états de santé et de recours aux soins [Thèse de santé publique]. Paris: Université Pierre et Marie Curie.

[18] WHO (2013) Oral health survey: basic methods. Available at: http://www.icd.org/content/publications/WHO-Oral-Health-Su rveys-Basic-Methods-5th-Edition-2013.pdf. 